\title{
$\beta$-Catenin Expression Regulates Cell Migration of Human Colonic Adenocarcinoma Cells Through Gelsolin
}

\author{
DAGMARA BACZYNSKA ${ }^{1}$, IZABELA BOMBIK ${ }^{2}$ and MARIA MALICKA-BŁASZKIEWICZ ${ }^{2}$ \\ ${ }^{1}$ Department of Forensic Medicine, Molecular Techniques Unit, Wroclaw Medical University, Wroclaw, Poland; \\ ${ }^{2}$ Department of Cell Pathology, Faculty of Biotechnology, University of Wroclaw, Wroclaw, Poland
}

\begin{abstract}
Background/Aim: $\beta$-Catenin is one of the key players in colonic carcinogenesis. Being part of the Ecadherin complex, it regulates cell-cell adhesion and the migratory ability of cells. However, the role of nuclear $\beta$ catenin in the cell migration process is poorly understood. Gelsolin is one of the most abundant actin-binding proteins, and is implicated in tumour cell motility and invasiveness. The aim of the present study was to evaluate the potential association between expression of $\beta$-catenin and gelsolin, and their influence on the migration ability of colon adenocarcinoma LS180 cells. Materials and Methods: The colonic adenocarcinoma cell line LS180, its more motile sublines $(E B 3,3 L N L N, 5 W)$ and $\beta$-catenin-knockdown LS180 cells were used to investigate the expression levels and subcellular localization of $\beta$-catenin and gelsolin. Results: Increased motility of colonic cancer cells was accompanied by a reduction of $\beta$-catenin and up-regulation of gelsolin. Conclusion: $\beta$-Catenin seems to be involved in the regulation of gelsolin expression, which in turn affects the migratory ability of colonic cancer cells. Our results could have important implications for the design of new anticancer therapies.
\end{abstract}

$\beta$-Catenin is a crucial protein for the regulation of cadherinmediated cell-cell adhesion. It binds to the cytoplasmic domain of cadherin and affects the actin cytoskeleton via $\alpha$ catenin (1). On the other hand, it acts as a transcriptional coactivator in the canonical WNT signaling pathway (2). Most $\beta$-catenin molecules are localized at adherens junctions $(\mathrm{AJs})$; only a small amount of the protein is present in the

Correspondence to: Dagmara Baczynska, Department of Forensic Medicine, Molecular Techniques Unit, Wroclaw Medical University, Sklodowska-Curie 52, 50-369, Wroclaw, Poland. Tel: +48 717841597, e-mail: dagmara.baczynska@umed.wroc.pl

Key Words: Cancer cell migration, colonic cancer, $\beta$-catenin, gelsolin. cytoplasm outside the AJs, due to rapid ubiquitin-mediated degradation by adenomatous polyposis coli (APC)-axinglycogen synthase kinase-3 $\beta$ (GSK-3 $\beta$ ) complex (3). Activation of the WNT pathway stabilizes $\beta$-catenin by GSK-3 $\beta$ inhibition, and increases its cytoplasmic accumulation and translocation in the nucleus. The association of $\beta$-catenin with transcription factor (TCF)/lymphoid enhancer binding factor (LEF) results in the transcription of genes responsible for cell proliferation (e.g. $\mathrm{v}$-myc avian myelocytomatosis viral oncogene homolog $(M Y C)$, peroxisome proliferator activated receptor delta (PPARD)), migration (matrix metallopeptidases 7 (MMP7) and 14 (MMP14)) and differentiation (transcription factor 4 (ITF2)) (4-7). Deregulation of WNT/ $\beta$-catenin signalling was found in many cancer types including colonic (8). Increased expression of $\beta$-catenin often occurs due to mutations within exon 3 of its gene $(C T N N B 1)$ or of the APC gene (9). $\beta$-Catenin is considered to be a good marker for early-stage colorectal carcinogenesis. Although its usefulness as a predictor of clinical outcome is still controversial, some studies have reported a correlation between nuclear accumulation of $\beta$-catenin and survival of patients with colorectal carcinoma $(10,11)$.

Cell migration is a multistep, complex process occurring during tumour invasion and metastasis. It requires dynamic and coordinated reorganization of the cytoskeletal network by numerous actin-binding proteins (ABPs) (12). Gelsolin is an $\mathrm{ABP}$ which controls the polymerization, as well as severing, of actin filaments. It has been reported to act as a key molecule during formation of invadopodia or podosomes, which are structures responsible for cell migration into the extracellular matrix (13). Gelsolin overexpression enhances fibroblast motility, in contrast to gelsolin-null cells (14). Similarly, gelsolin silencing by RNA interference (RNAi) in pancreatic, prostate and breast cancer cells results in a reduction of cell motility $(15,16)$. Furthermore, down-regulation of gelsolin expression has been observed in many tumours and was found to be a useful marker of tumour progression and invasion $(17,18)$. 
The role of $\beta$-catenin in cell adhesion and motility via regulation of AJs is well established. However, less well known is the influence of its nuclear activity on ABP expression. As an experimental model, we used the human colonic adenocarcinoma LS180 cell line and its three selected variants characterized by different metastatic and motility capacity (EB3, 5W, 3LNLN) $(19,20)$.

\section{Materials and Methods}

Cell lines and culture conditions. As an experimental model we used LS180 human colonic adenocarcinoma cell line and its sublines EB3, 3LNLN and, 5W, obtained from the Institute of Immunology and Experimental Therapy (Polish Academy of Sciences in Wroclaw, Poland). All cell lines were maintained in OptiMEM medium (Gibco, Paisley, UK) supplemented with 3\% foetal bovine serum (FBS; Gibco), $2 \mathrm{mM}$ glutamine (Gibco) and $1 \%$ penicillin-streptomycin (Gibco), and cultured at $37^{\circ} \mathrm{C}$ under $5 \%$ $\mathrm{CO}_{2}$ in a humidified incubator.

Primary antibodies. Purified mouse anti-human $\beta$-catenin (clone 14; BD Biosciences, San Jose, CA, USA) and mouse anti-human $\alpha-$ catenin (clone 5; BD Biosciences) were diluted 1:1,000 and 1:500 for western blot, respectively. Monoclonal mouse anti-gelsolin antibody (clone GS-2C4; Sigma-Aldrich, St. Louis, MO, USA) was used at 1:1,000 dilution for western blot. For immunofluorescence analysis, all antibodies were diluted 1:100.

RNA interference. The pool of four ON-TARGETplus SMARTpool CTNNB1 small interfering RNAs (siRNAs) (L-003482-00-0005; Dharmacon, Lafayette, CO, USA) specifically targeting CTNNB1 (NM_001904) was used for silencing of $\beta$-catenin expression. ONTARGETplus Non-targeting Control Pool siRNA (Dharmacon) was used as a negative control. LS180 cells were seeded $24 \mathrm{~h}$ before transfection at a density of $3 \times 10^{5}$ cells/well and subsequently transfected with $5 \mathrm{nM}$ siRNA and DharmaFECT 4 transfection reagent (Dharmacon) according to the manufacturer's protocol. Cells were harvested after $48 \mathrm{~h}$ for quantitative real-time polymerase chain reaction (qRT-PCR) analysis. Western blot, aggregation, adhesion and immunofluorescence assays were carried out 72 and $96 \mathrm{~h}$ after transfection.

$q R T-P C R$ analysis. Total RNA was prepared using a NucleoSpin RNA II isolation kit (Macherey-Nagel, Düren, Germany). Firststrand cDNA was synthesized using a ThermoScript RT-PCR System (Invitrogen). Relative amounts of the analysed mRNAs were measured by real-time PCR method using TaqMan Fast Universal PCR Master Mix (Applied Biosystems, Foster City, CA, USA) and specific TaqMan Gene Expression Assays (Hs99999168_m1 for $\beta$-catenin, Hs00426996 for $\alpha$-catenin, Hs00609276_m1 for gelsolin and Hs99999905_m1 for GAPDH). All reactions were carried out in triplicate. The real-time PCR was performed on a 7900HT Fast Real-Time PCR System (Applied Biosystems) under the following thermal cycling conditions: $20 \mathrm{~s}$ at $95^{\circ} \mathrm{C}$ and 40 cycles of $1 \mathrm{~s}$ at $95^{\circ} \mathrm{C}$ and $20 \mathrm{~s}$ at $60^{\circ} \mathrm{C}$. For quantification, samples were normalized against the expression of glyceraldehyde 3-phosphate dehydrogenase $(G A P D H)$. Relative quantification (RQ) for the examined mRNAs was calculated using the $2^{-\Delta \Delta C T}$ method.
Western blot assay. Total protein extract was prepared from cells using a lysis buffer (50 mM Tris-HCl, $\mathrm{pH} 8.0,150 \mathrm{mM} \mathrm{NaCl}, 1 \%$ NP-40, $0.1 \%$ SDS, $0.5 \%$ sodium deoxycholate) supplemented with protease inhibitor cocktail and phenylmethylsulfonyl fluoride (Sigma-Aldrich). Cytosolic fractions were isolated from cells using a Dounce homogenizer with stabilizing buffer $[10 \mathrm{mM}$ Tris- $\mathrm{HCl}$, (pH 7.4), $1 \mathrm{mM}$ dithiothreitol, $0.1 \mathrm{mM}$ ATP, $0.1 \mathrm{mM} \mathrm{CaCl}_{2}$ and 0.25 $\mathrm{M}$ sucrose] as described previously (21). Nuclear proteins were prepared using lysis buffer (50 mM Tris- $\mathrm{HCl}, \mathrm{pH} 8.0,50 \mathrm{mM} \mathrm{NaCl}$, $1 \%$ Triton $\mathrm{X}-100,0.1 \%$ sodium dodecyl sulfate (SDS), $1 \% \mathrm{v} / \mathrm{v}$ inhibitor cocktail, $1 \mathrm{mM}$ phenylmethylsulfonyl fluoride) supplemented with increasing concentrations of sucrose (0-0.8 M) as described by Wiedłocha et al. (22). Protein concentrations were determined using a BCA Protein Assay Kit (Pierce, Rockford, IL, USA) according to the manufacturer's protocol. Protein samples were separated on $10 \%$ gel in SDS- polyacrylamide gel electrophoresis and transferred onto a nitrocellulose membrane (Sigma-Aldrich). After blocking with 5\% non-fat dried milk solution, the membranes were incubated at $4{ }^{\circ} \mathrm{C}$ overnight with primary antibodies diluted as described above. Blots were developed using a Mouse ExtrAvidin Peroxidase Staining Kit (Sigma-Aldrich) and 3-amino-9-ethylcarbazole (Sigma-Aldrich). Three independent experiments were performed for each analysis.

Confocal microscopy. Cells were washed with PBS and fixed with $4 \%$ paraformaldehyde. After permeabilization with $0.1 \%$ Triton X100 in PBS, cells were incubated with primary antibodies for $1 \mathrm{~h}$. Anti-mouse secondary antibodies conjugated with fluorescein isothiocyanate (FITC) or DyLight 549 (Jackson ImmunoResearch, West Grove, PA, USA) were used according to the manufacturer's instructions. Actin filaments were stained with Alexa Fluor 568labelled phalloidin (Invitrogen). All analyses were performed using an Olympus FV 500 confocal laser scanning microscope (Olympus Co., Tokyo, Japan).

Cell-migration assay. Cell motility was tested using Boyden chambers with $8-\mu \mathrm{m}$ pore size inserts exactly as described previously $(21) ; 5 \times 10^{4}$ cells were seeded for each test. All experiments were performed three times.

Cell-adhesion assay. The cell-adhesion assay was performed using a Vybrant Cell Adhesion Assay Kit (Molecular Probes, Eugene, OR, USA). Parental and siRNA-transfected LS180 cells were seeded at a density of $1 \times 10^{5}$ cells/well on a clear-bottom, black 96-well plate and cultured for $24 \mathrm{~h}$. Adherent non-transfected and siRNA-transfected cells were detached using $2 \mathrm{mM}$ EDTA in Hank's solution, counted and washed twice with PBS. Cells were then resuspended at a density of $4 \times 10^{5}$ cells $/ \mathrm{ml}$ in MEM alpha with $5 \mu \mathrm{M}$ calcein AM and incubated for $30 \mathrm{~min}$ at $37^{\circ} \mathrm{C}$. Stained cells were washed twice with pre-warmed MEM alpha, resuspended in MEM alpha at $8 \times 10^{5}$ cells $/ \mathrm{ml}$ and then added at a density of $8 \times 10^{4}$ cells/well on top of confluent monolayer cultures of parental and siRNA-transfected cells onto a 96-well plate. After $1 \mathrm{~h}$ of incubation at $37^{\circ} \mathrm{C}$, unattached cells were removed by washing with PBS. Calcein AM fluorescence in labelled cells was measured at $520 \mathrm{~nm}$. The percentage adhesion was calculated as the ratio of the fluorescence of attached cells to that of the total cells added to each well. All values were estimated relative to nontransfected LS180 cells. Cells treated with anti-E-cadherin were used as a negative control. 
Aggregation assay. Colonic adenocarcinoma cells were harvested using 2 mM EDTA in Hank's solution ( $\mathrm{pH} 7.4)$ and then suspended in OptiMEM medium supplemented with $1 \%$ FBS at a density of $2 \times 10^{5}$ cells $/ \mathrm{ml}$. The assay was performed as described previously (23).

Proliferation assay. LS180 cells were seeded onto a 96-well plate at a density of $2 \times 10^{3}$ cells/well and transfected with siRNA under the conditions described above. The number of cells was determined $24,48,72$ and $96 \mathrm{~h}$ after transfection by the sulforhodamine B method, as described previously (23).

Statistical analysis. All results are expressed as the mean \pm standard deviation (SD) of three replicates and are representative of at least three independent experiments. Data were analysed by unpaired Student's $t$-test with a value of $p<0.05$ being considered statistically significant.

\section{Results}

Expression of $\beta$-catenin and gelsolin in LS180 cells with different migratory ability. LS180 Colonic adenocarcinoma cell line and its three selected in vitro and in vivo variants with increasing migratory and metastatic potential (EB3, $3 \mathrm{LNLN}, 5 \mathrm{~W})$ were used in this study $(19,20)$. In order to investigate a relationship between migration of the cells and the expression of catenins and gelsolin, $\mathrm{qPCR}$ and immunoblotting analyses were performed (Figure 1A). $\beta$ Catenin mRNA was slightly elevated in more motile cancer cells. The highest level of its transcripts was observed in $5 \mathrm{~W}$ cells (RQ $1.40 v s$. parental LS180 cells, $p<0.01$ ). In contrast, the $\alpha$-catenin mRNA level decreased in the EB3 and 3LNLN sublines (RQ $0.75, p<0.05$ and $0.81, p<0.05$, respectively). Up-regulation of gelsolin transcripts was accompanied by increasing migration of cell lines, and the highest level was observed in $5 \mathrm{~W}$ cells, similarly to $\beta$-catenin (RQ 3.52, $p<0.01$ ).

Given that $\beta$-catenin can be found in different subcellular locations, analysis of the protein levels was performed in total cell extract and both cytosolic and nuclear fractions (Figure 1B). $\beta$-Catenin was decreased in whole-cell lysates as well as in the cytosolic fraction of more invasive and motile cell lines $(5 \mathrm{~W}, 3 \mathrm{LNLN})$. The expression of $\beta$-catenin in total cell extract and the cytosolic fraction of $5 \mathrm{~W}$ cells was significantly lower than that in LS180 $(p<0.001$ and $p=0.003$, respectively). In contrast, its level in the nucleus tended to be increased in $5 \mathrm{~W}$ cells; however, the results were not statistically significant $(p=0.077)$. Furthermore, we analysed protein levels of $\alpha$-catenin and gelsolin in total cell extracts (Figure 1C). In comparison to LS180 cells, an increased level of gelsolin was detected in 5W and 3LNLN cells, while the $\alpha$-catenin level was similar in all investigated cell lines.

In order to determine whether the changes in $\beta$-catenin and gelsolin expression in LS180 colonic adenocarcinoma variants affected their intercellular adhesion, an
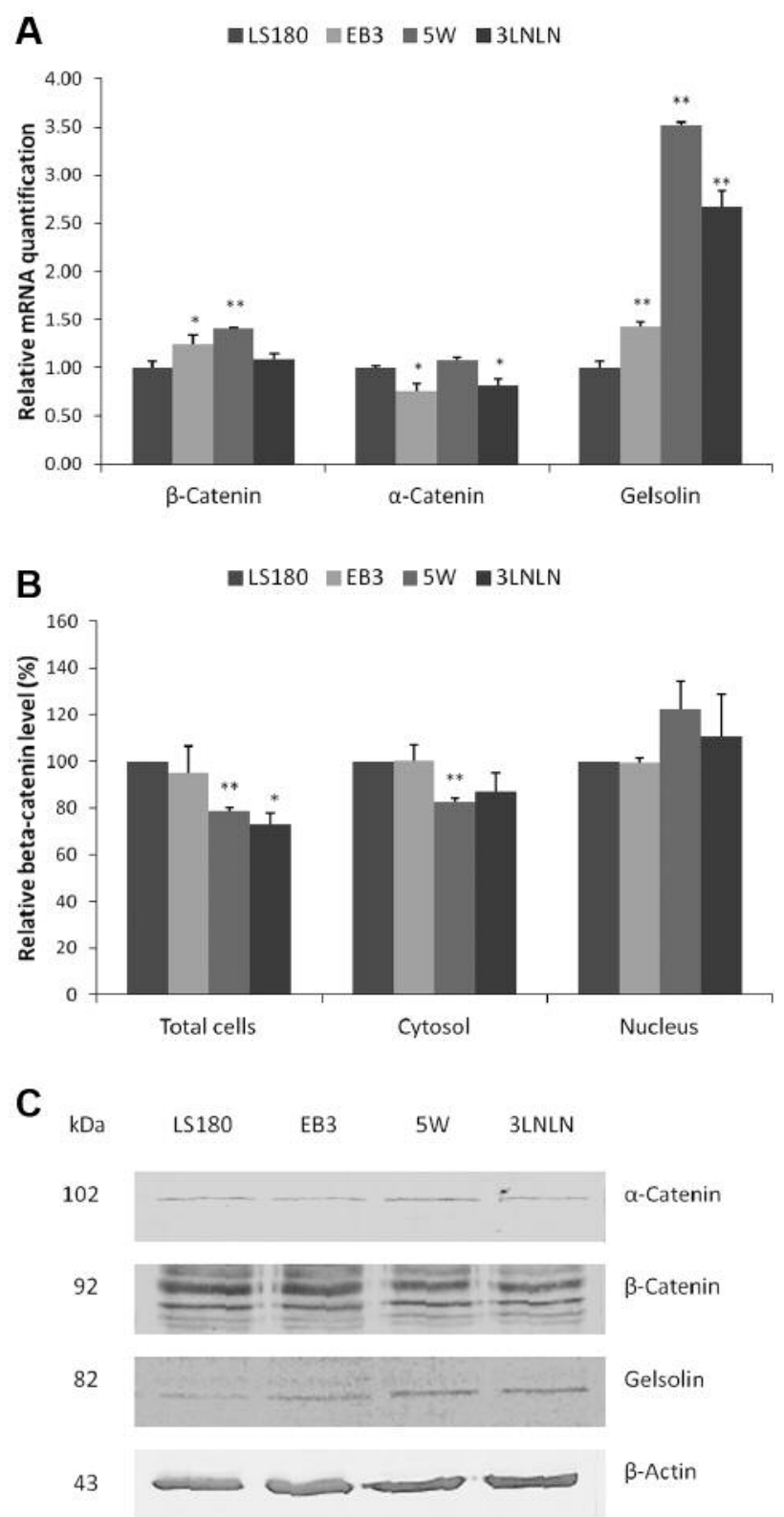

Figure 1. Impact of cell migration ability on the expression of gelsolin and catenins. A: The mRNA level of catenins and gelsolin was analyzed using real-time polymerase chain reaction assay. Relative $m R N A$ quantification was calculated using the 2- $\Delta \triangle C T$ model. All samples were normalized against internal expression of glyceraldehyde-3-phosphate dehydrogenase (GAPDH). LS180 cells were used as a calibrator. All measurements were made in triplicate and are presented as the mean $\pm S D$ for a representative experiment. B: Densitometric analysis of $\beta$-catenin amounts in total cell extract, cytosolic and nuclear fractions of colonic cancer cells. The mean density of protein bands was measured for three independent experiments. Results were related as a percentage of LS180 cells. C: Identification of catenins and gelsolin in total cell extract using specific monoclonal antibodies, as described in the Materials and Methods section. $\beta$-Actin was used as an internal control. For $\beta$-catenin, E-cadherin and $\beta$-actin, $20 \mu \mathrm{g}$ protein were used, while for $\alpha$-catenin and gelsolin detection, $50 \mu \mathrm{g}$ of total protein were used. ${ }^{*} p<0.05,{ }^{*} p<0.01$ by Student's t-test vs. LS180 cells. 


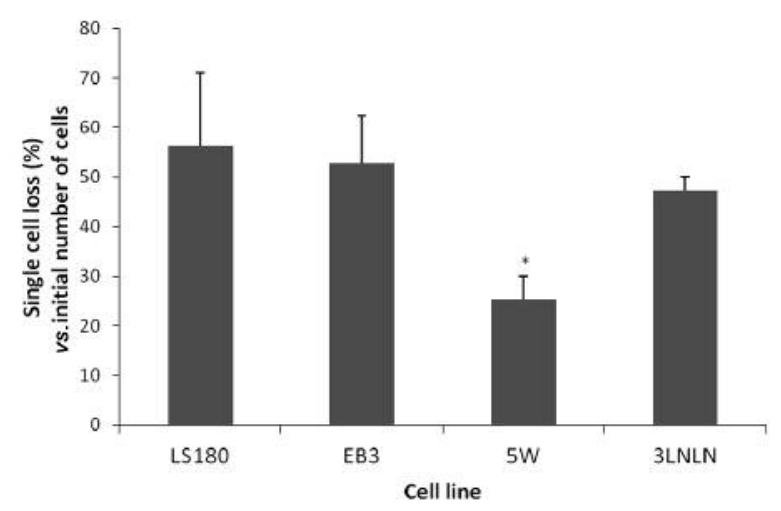

Figure 2. Effect of colonic cancer cell metastatic potential on cell-cell adhesion ability. The aggregation assay was performed with LS180 cells and EB3, $5 W$ and $3 L N L N$ cell sublines. Intercellular adhesion was measured as single cell loss over time. The cell number at the start of the experiment was determined as $100 \%$. Results are presented as the mean $\pm S D$ of three independent experiments, after $1 \mathrm{~h}$ incubation. $* p<0.05$ vs. LS180 cells by Student's t-test.

aggregation assay was performed (Figure 2). The ability of $5 \mathrm{~W}$ cells to form homotypic cell-cell interactions significantly decreased (by $\sim 50 \% ; p=0.025$ ) compared to parental LS180 cells.

Effect of $\beta$-catenin silencing on gelsolin expression. In order to investigate whether down-regulation of $\beta$-catenin affects gelsolin expression, transfection of LS180 cells was performed using a mixture of four siRNAs specific for the $\beta$-catenin gene $(C T N N B 1)$. Additionally, to determine whether transfection conditions influenced $\beta$-catenin expression, we used control siRNA as well as DharmaFECT 4 transfection reagent (DF4). The $\beta$-catenin mRNA level was suppressed by at least $75 \%$ at $48 \mathrm{~h}$ after transfection (Figure $3 \mathrm{~A}$ and $\mathrm{B}$ ) and a reduced protein level was found in total cell extract at $72 \mathrm{~h}$ after transfection (Figure 3C). The loss of $\beta$-catenin resulted in increased expression of gelsolin at both mRNA and protein levels (Figure 3 A-C).

Down-regulation of $\beta$-catenin enhances the migration ability of LS180 cells. The morphology of cells with downregulated $\beta$-catenin expression varied more than that of parental cells (Figure 4). Some were more spread and polygonal, whereas others presented a rounded shape. Furthermore, we found a dramatic reorganization of the actin cytoskeleton in RNAi-treated cells (Figure 4D and H); $48 \mathrm{~h}$ and $72 \mathrm{~h}$ after siRNA transfection, we observed thinner marginal actin bundles at the free edges of contacting cells, as well as at the site of the cell-cell contact. The changes in morphology and of the actin cytoskeleton were accompanied
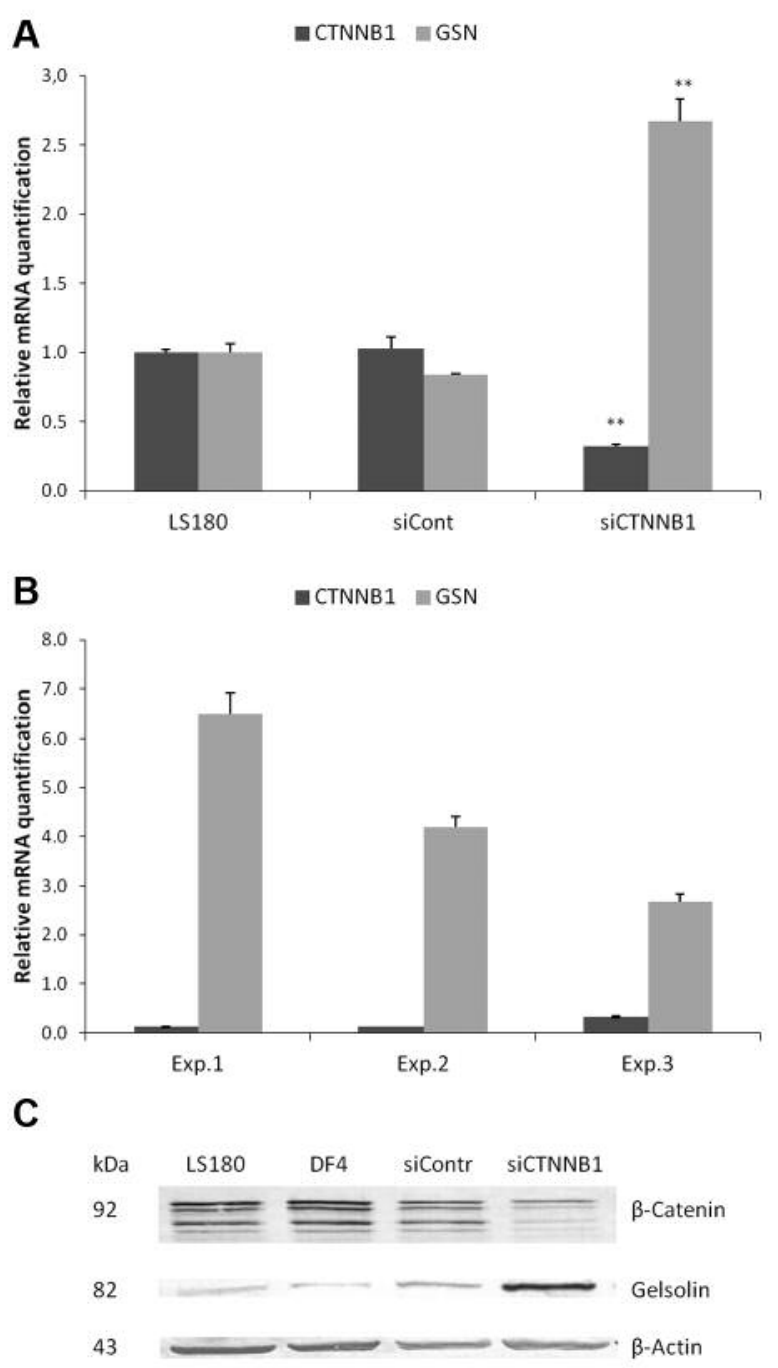

Figure 3. Effect of $\beta$-catenin down-regulation on gelsolin expression. A: Non-transfected cells (LS180) as well as cells transfected with control siRNA (siControl) and siRNA targeted to $\beta$-catenin (siCTNNB1) were used for analysis. The level of catenin (CTNNB1) and gelsolin (GSN) was analyzed using real-time polymerase chain reaction assay. Relative mRNA quantification was calculated using the $2^{-\Delta \Delta C T}$ model. All samples were normalized against internal expression of glyceraldehyde3-phosphate dehydrogenase (GAPDH). LS180 cells were used as a calibrator. All measurements were made in triplicate and are presented as the mean $\pm S D$ for a representative experiment. B: Relationship between rate of $\beta$-catenin silencing and expression of gelsolin mRNA. Results are presented for three independent experiments. $C$ : Identification of $\beta$-catenin and gelsolin in total cell extract using specific monoclonal antibodies as described in the Materials and Methods. For $\beta$-catenin, $10 \mu \mathrm{g}$ protein were used, while for gelsolin detection, $30 \mu \mathrm{g}$ of protein were used. ${ }^{*} p<0.01 \mathrm{vs}$. untreated LS180 cells in Student's t-test.

by a decreasing number of AJs, identified as dots in the cell-cell contact space by E-cadherin immunostaining (Figure 4B and F). 


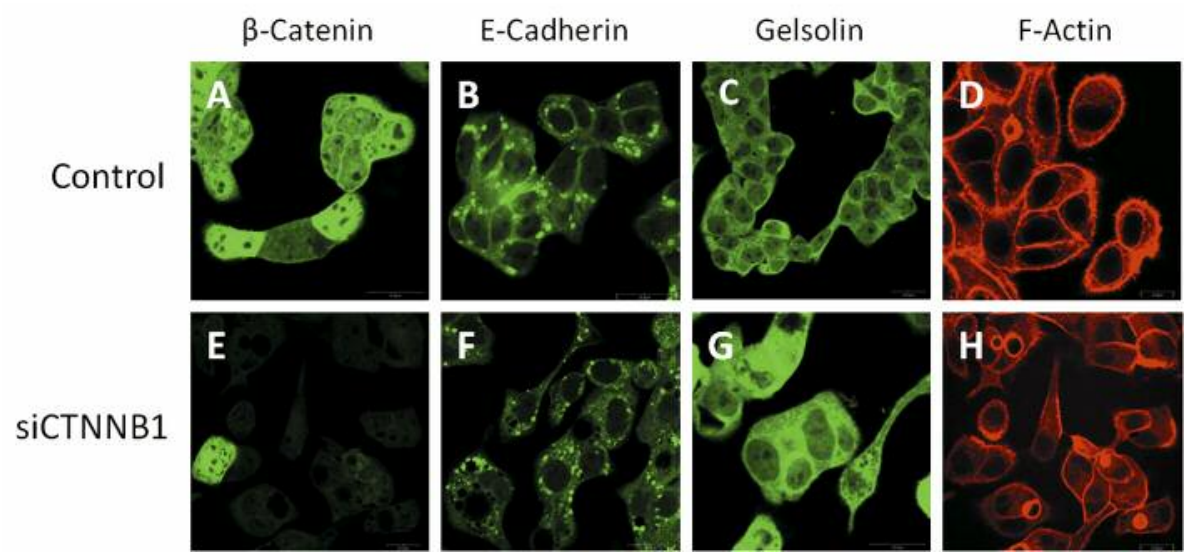

Figure 4. Cellular localization of adherens junctions proteins and gelsolin in $\beta$-catenin down-regulated cells. $\beta$-Catenin $(A, E), E$-cadherin $(B, F)$, gelsolin $(C, G)$ and filamentous actin $(D, H)$ were detected as described in the Materials and Methods (green). Filamentous actin was visualized using Alexa Fluor 568-conjugated phalloidin.

Several studies have shown that $\beta$-catenin regulates cancer cell proliferation and survival [for a review, see Valenta et al. (24)]. Despite this fact, we did not observe any effect of $\beta$-catenin down-regulation on the rate of cell growth determined by sulforhodamine B assay (Figure 5A).

In order to assess whether changes in morphology could affect cell motility, a modified Boyden chamber migration assay was performed. LS180 cells with a decreased level of $\beta$-catenin had significantly higher migratory ability compared to untransfected controls (Figure 5B). The number of siRNA-treated cells migrating through Transwell filters was 3.76-fold higher than that of parental, untreated cells $(p<0.001)$. The lower migratory ability of these cells was accompanied by decreased intercellular adhesion. Whereas the inhibition of E-cadherin contacts in non-transfected LS180 cells by monoclonal antibodies resulted in a greater than eight-fold reduction ( $p=0.008 v s$. control cells) in cellcell adhesion, the number of cell-cell contacts was decreased almost two-fold ( $p=0.017 v s$. control cells) in the case of $\beta$ catenin down-regulated cells (Figure 5C).

\section{Discussion}

An antisense strategy based on siRNA and microRNA is a promising and highly potent method for anticancer therapy. Both types of molecules are able to down-regulate the expression of specific genes and mRNA transcripts; however, their mechanisms of action are distinct [for a review, see Lam et al. (25)]. Here, we applied an RNAi strategy to develop its usefulness to anti-colonic cancer therapy, by targeting $\beta$-catenin mRNA. Our results were additionally verified in colonic adenocarcinoma cells which differ in metastatic and migratory potential.
$\beta$-Catenin is considered to be a key protein engaged in the initiation and progression of colorectal cancer. Its nuclear accumulation is associated with poor prognosis for patients; however, its role in metastasis is still unclear $(10,11,26)$. It is supposed that $\beta$-catenin translocation into the nucleus promotes metastasis via both the destruction of E-cadherin complexes and the induction of MMP expression $(2,5,7)$. Whereas some groups reported a relationship between nuclear/membrane $\beta$-catenin expression and invasiveness of colorectal cancer, others did not find any association of $\beta$ catenin level with either tumour stage or tumour grade (2729). These conflicting data may be due to the distinct experimental methodology, as well as biological differences between rectal and colonic carcinomas. Aamodt et al. found significant differences in $\beta$-catenin expression between rectal and colonic carcinoma (30). For this reason, we decided to use the well-characterized LS180 cell line and its selected variants EB3, 5W and 3LNLN in our research. In our study, cells metastasizing into liver (5W) and lymph nodes (3LNLN) had significantly lower amounts of $\beta$-catenin in both the total cell extract and cytosolic fraction, accompanied by an increased nuclear fraction of $\beta$-catenin. $\alpha$-Catenin, another protein engaged in forming AJs, remained at a similar level in all analyzed cell lines. We suppose that decreased expression of $\beta$-catenin might be involved in weakening of cell-cell contacts in the $5 \mathrm{~W}$ subline, observed as an increased number of singular cells in suspension during the aggregation test.

The experimental data showed evident, negative correlation between gelsolin and $\beta$-catenin expression. In the $5 \mathrm{~W}$ and 3LNLN sublines, characterized by low $\beta$-catenin expression, gelsolin was significantly elevated. In addition, gelsolin was positively associated with cellular migratory ability. The 

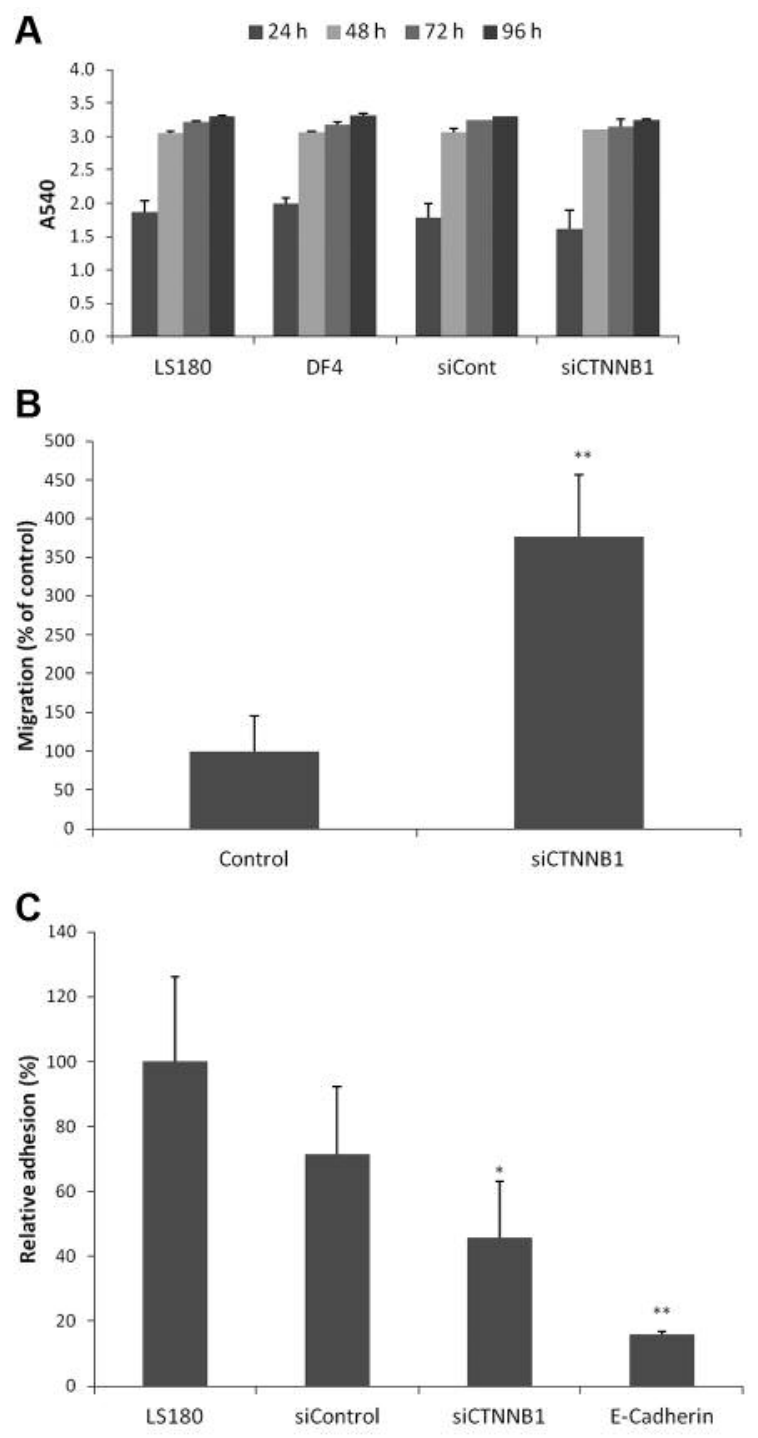

Figure 5. Effect of $\beta$-catenin down-regulation on the migration and intercellular adhesion ability of LS180 cells. A: Cell proliferation was determined by the sulforhodamine $B$ test. Results are presented as mean $\pm S D$ absorbance measured at $540 \mathrm{~nm} ; n=3$. B: Cell migration was investigated using Transwell filters. Results are presented as mean $\pm S D$ for three independent experiments. Migration of non-transfected cells was set at 100\%. C: Intercellular interaction was identified using a Vybrant Cell Adhesion Assay Kit. Non-transfected and siRNA-transfected cells were labelled with calcein in suspension and then applied onto confluent culture of LS180 cells in a 96-well plate. As a negative control, cells treated with anti-E-cadherin antibodies were used, while non-transfected cells were used as a positive control (100\% adhesion). After $1 \mathrm{~h}$ of incubation and slight washing of non-binding cells, fluorescence measurement of calcein-stained cells was performed. Results are presented as mean $\pm S D ; n=4 .{ }^{*} p<0.05$, ${ }^{* *} p<0.01$ vs. untreated LS180 cells by Student's t-test.

relationship between up-regulation of gelsolin and increased motility of LS180 cells was previously shown by Litwin $\mathrm{et} \mathrm{al}$. (21). Gelsolin overexpression in LS180 cells stimulated the formation of podosome-like structures and increased the migratory potential of the cells (21). Similarly, gelsolin overexpression promoted the migration and invasion of human oral carcinoma cells and colorectal tumour cells $(31,32)$. Despite these observations, its role in cancer progression remains controversial. Some immunohistochemical studies reported a reduced expression of gelsolin during colon carcinogenesis $(18,33)$. Our findings indicate the potential involvement of gelsolin in the promotion of metastasis.

In order to confirm the effect of $\beta$-catenin on gelsolin expression and the migration of colonic adenocarcinoma cells, we suppressed its expression with siRNA in parental LS180 cells. The silencing of $\beta$-catenin resulted in an increase in both mRNA and protein levels of gelsolin. Down-regulation of $\beta$ catenin with concomitant overexpression of gelsolin led to a significant increase of cell migratory capacity and the weakening of intercellular interactions. Interestingly, our results may explain the association of low $\beta$-catenin expression with metastasis of some cancer types $(34,35)$.

By contrast, other studies indicated the opposite role of $\beta$ catenin in colonic cancer metastasis. Han et al. showed that siRNA-mediated down-regulation of $\beta$-catenin resulted in suppression of invasiveness and migration of the colonic cancer cell line LoVo, which was accompanied by increased cellular homotypic adhesion (36). It is possible that the discrepancies in results were caused by pathomorphological differences of these two cell lines. LS180 cells are welldifferentiated colonic adenocarcinoma isolated from a primary tumour with Dukes' stage B and an S45 mutation within $\beta$-catenin, whereas LoVo cells derived from poorly differentiated metastasis (Dukes' stage D) with wild-type $\beta$ catenin but APC truncation (37). Taken together, the results indicated that there are two distinct pathways of $\beta$-catenin action in cancer cells. However, the mechanism of switching between them has still not been uncovered and requires further studies.

In conclusion, we demonstrated that inhibition of $\beta$ catenin expression can increase the migratory ability of colonic adenocarcinoma cells. Furthermore, gelsolin was identified as a potential migration mediator, remaining under $\beta$-catenin control. Our observation could have a significant impact on the development of anticancer therapies based on targeting $\beta$-catenin and the WNT signaling pathway. We suspect that, paradoxically, antisense therapy directed against $\beta$-catenin could promote cancer invasiveness and development of metastases in some cases.

\section{Acknowledgements}

This work was supported by the Polish Ministry of Science and Higher Education grant NN302 138035.

The Authors would like to thank Liliana Kiczak for critical reading of the manuscript. 


\section{References}

1 Dress F, Pokutta S, Yamada S, Nelson WJ and Weis WI: $\alpha$ Catenin is a molecular switch that binds E-cadherin- $\beta$-catenin and regulates actin-filament assembly. Cell 123: 903-915, 2005.

2 Cong F, Schweizer 1, Chamorro $M$ and Varmus H: Requirement for a nuclear function of beta-catenin in Wnt signaling. Mol Cell Biol 23: 8462-8470, 2003.

3 Rubinfeld B, Albert I, Porfiri E, Fiol C, Munemitsu S and Polakis P: Binding of GSK3beta to the APC- $\beta$-catenin complex and regulation of complex assembly. Science 272: 1023-1026, 1996.

4 He TC, Chan TA, Vogelstein B and Kinzler KW: PPARdelta is an APC-regulated target of nonsteroidal anti-inflammatory drugs. Cell 99: 335-345, 1999.

5 Brabletz T, Jung A, Dag S, Hlubek F and Kirchner T: $\beta$-catenin regulates the expression of the matrix metalloproteinase-7 in human colorectal cancer. Am J Pathol 155: 1033-1038, 1999.

6 Kolligs FT, Nieman MT, Winer I, Hu G, Van Mater D, Feng Y, Smith IM, Wu R, Zhai Y, Cho KR and Fearon ER: ITF-2, a downstream target of the Wnt/TCF pathway, is activated in human cancers with $\beta$-catenin defects and promotes neoplastic transformation. Cancer Cell 1: 145-155, 2002.

7 Hlubek F, Spaderna S, Jung A, Kirchner T and Brabletz T: Betacatenin activates a coordinated expression of the proinvasive factors laminin-5 gamma 2 chain and MT1-MMP in colorectal carcinomas. Int J Cancer 108: 321-326, 2004.

8 White BD, Chien AJ and Dawson DW: Dysregulation of Wnt/ßcatenin signaling in gastrointenstinal cancers. Gastroenterology 142: 219-232, 2012.

9 Morin PJ, Sparks AB Korinek V, Barker N, Clevers H, Vogelstein B and Kinzler KW: Activation of $\beta$-catenin-Tcf signaling in colon cancer by mutations in $\beta$-catenin or APC. Science 275: 1787-1790, 1997.

10 Elzagheid A, Buhmeida A, Korkeila E, Collan Y, Syrjanen K and Pyrhonen S: Nuclear $\beta$-catenin expression as a prognostic factor in advanced colorectal carcinoma. World J Gastroenterol 14: 3866-3871, 2008.

11 Yoshida N, Kinugasa T, Ohshima K, Yuge K, Ohchi T, Fujino S, Shiraiwa S, Katagiri M and Akagi Y: Analysis of Wnt and $\beta$ catenin expression in advanced colorectal cancer. Anticancer Res 35: 4403-4410, 2015

12 Yamaguchi $\mathrm{H}$ and Condeelis $\mathrm{J}$ : Regulation of the actin cytoskeleton in cancer cell migration and invasion. Biochim Biophys Acta 1773: 642-652, 2007.

$13 \mathrm{Hu} \mathrm{S}$, Biben T, Wang X, Jurdic P and Géminard JC: Internal dynamics of actin structures involved in the cell motility and adhesion: Modeling of the podosomes at the molecular level. J Theor Biol 270: 25-30, 2011.

14 Cunningham CC, Stossel TP and Kwiatkowski DJ: Enhanced motility in NIH 3T3 fibroblasts that overexpress gelsolin. Science 251: 1233-1236, 1991.

15 Thompson CC, Ashcroft FJ, Patel SG, Vimalachandran D, Prime W, Campbell F, Dodson A, Jenkins RE, Lemoine NR, Crnogorac-Jurcevic T, Yin HL and Costello E: Pancreatic cancer cells overexpress gelsolin family-capping proteins, which contribute to their cell motility. Gut 56: 95-106, 2007.

16 Van den Abbeele A, De Corte V, Van Impe K, Bruyneel E, Boucherie C, Bracke M, Vandekerckhove J and Gettemans J: Down-regulation of gelsolin family proteins counteracts cancer cell invasion in vitro. Cancer Lett 255: 57-70, 2007.
17 Winston JS, Asch HL, Zhang PJ, Edge SB, Hyland A and Asch BB: Down-regulation of gelsolin correlates with the progression to breast carcinoma. Breast Cancer Res Treat 65: 11-21, 2001.

18 Gay F, Estornes Y, Saurin JC, Joly-Pharaboz MO, Friederich E, Scoazec JY and Abello J: In colon carcinogenesis, the cytoskeletal protein gelsolin is down-regulated during the transition from adenoma to carcinoma. Hum Pathol 39: 1420$1430,2008$.

19 Opolski A, Wietrzyk J, Duś D, Kieda C, Matejuk A, Makowska A, Wojdat E, Ugorski M, Laskowska A, Kłopocki A, Rygaard J and Radzikowski C: Metastatic potential and saccharide antigens expression of human colon cancer cells xenotransplanted into athymic nude mice. Folia Microbiol 43: 507-510, 1998.

20 Nowak D, Mazur AJ, Popow-Woźniak A, Radwańska A, Mannherz HG and Malicka-Błaszkiewicz M: Subcellular distribution and expression of cofilin and ezrin in human colon adenocarcinoma cell lines with different metastatic potential. Eur J Histochem 54: e14, 2010.

21 Litwin M, Nowak D, Mazur AJ, Baczyńska D, Mannherz HG and Malicka-Błaszkiewicz M: Gelsolin affects the migratory ability of human colon adenocarcinoma and melanoma cells. Life Sci 90: 851-861, 2012.

22 Wiedłocha A, Nilsen T, Wesche J, Sorensen V, Małcki J, Marcinkowska E and Olsnes S: Phosphorylation-regulated nucleocytoplasmic trafficking of internalized fibroblast growth factor-1. Mol Biol Cell 16: 794-810, 2005.

23 Baczyńska D, Wietrzyk J, Madej J, Krop-Watorek A, Dabrowska A, Widerak K, Opolski A and Ugorski M: The tumorigenic potential of human CX-1 colon adenocarcinoma cells depends on carcinoembryonic antigen (CEACAM5) expression. Cell Mol Biol Lett 8: 471-486, 2003.

24 Valenta T, Hausmann $\mathrm{G}$ and Basler K: The many faces and functions of $\beta$-catenin. EMBO J 32: 2714-2736, 2012.

25 Lam JKW, Chow MYT, Zhang Y and Leung SWS: siRNA vesrsus miRNA as therapeutics for gene silencing. Mol Ther Nucleic Acids 4: e525, 2015.

26 Chen Z, He X, Jia M, Qu D, Wu D, Wu P, Ni Ch, Zhang Z, Ye $\mathrm{J}, \mathrm{Xu} \mathrm{J}$ and Huang $\mathrm{J}$ : $\beta$-catenin overexpression in the nucleus predicts progress disease and unfovourable survival in colorectal cancer: a meta-analysis. Plos One 8: e63854, 2013.

27 Suzuki H, Masuda N, Shimura T, Araki K, Kabayashi T, Tsutsumi S, Asao $\mathrm{T}$ and Kuwano $\mathrm{H}$ : Nuclear $\beta$-catenin expression at the invasive front and in the vessels predicts liver metastasis in colorectal carcinoma. Anticancer Res 28: 18211830, 2008.

28 Brabletz T, Jung A, Reu S, Porzner M, Hlubek F, KunzSchughart LA, Knuechel R and Kircher T: Variable $\beta$-catenin expression in colorectal cancers indicates tumor progression driven by the tumor environment. Proc NatI Acad Sci USA 98: 10356-10361, 2001.

29 Hugh TJ, Dillon SA, O’Dowd G, Getty B, Pignatelli M, Poston GJ and Kinsella AR: $\beta$-catenin expression in primary and metastatic colorectal carcinoma. Int J Cancer 82: 504-511, 1999.

30 Aamodt R, Bondi J, Andersen SN, Bakka A, Bukholm G and Bukholm IR: The prognostic impact of protein expression of Ecadherin-catenin complexes differs between rectal and colon carcinoma. Gastroenterol Res Pract, ID: 616023, 2010.

31 Deng R, Hao J, Ni Y, Huang X and Hu Q: Gelsolin regulates proliferation, apoptosis, migration and invasion in human oral carcinoma cells. Oncol Lett 9: 2129-2134, 2015. 
32 Zhuo J, Tan EH, Yan B, Tochhawng L, Jayapal M, Koh S, Tay HK, Maciver SK, Hooi SC, Salto-Tellez M, Kumar AP, Goh YC, Lim YC and Yap CT: Gelsolin induces colorectal tumor cell invasion via modulation of the urokinase-type plasminogen activator cascade. PlosOne 7: e43594, 2012.

33 Furuuchi K, Fujita H, Tanaka M, Shitinohe T, Senmaru N, Ogiso Y, Moriya S, Hamada M, Kato H and Kuzumaki N: Gelsolin as a suppressor of malignant phenotype in human colon cancer. Tumor Target 2: 277-83, 1997.

34 Garcia-Rostan G. Camp RL, Herrero A, Carcangiu ML, Rimm DL and Tallini G: Beta-catenin dysregulation in thyroid neoplasms: down-regulation, aberrant nuclear expression, and CTNNB1 exon 3 mutations are markers for aggressive tumor phenotypes and poor prognosis. Am J Pathol 158: 987-986, 2001.

35 Ebert MP, Yu J, Hoffmann J, Rocco A, Röcken C, Kahmann S, Müller O, Korc M, Sung JJ and Malfertheiner P: Loss of betacatenin expression in metastatic gastric cancer. J Clin Oncol 21: 1708-1714, 2003.
36 Han J, Gao B, Jin X, Xu Z, Li Z, Sun Y and Song B: Small interfering RNA-mediated down-regulation of beta-catenin inhibits invasion and migration of colon cancer cells in vitro. Med Sci Monit 18: BR273-280, 2012.

37 Rosin-Arbesfeld R, Cliffe A, Brabletz T and Bienz M: Nuclear export of the APC tumour suppressor controls beta-catenin function in transcription. EMBO J 22: 1101-1113, 2003.
Received August 18, 2016

Revised September 13, 2016

Accepted September 15, 2016 